\title{
Sickle cell retinopathy in young children in Jamaica
}

\author{
J. F. TALBOT, ${ }^{\prime}$ A. C. BIRD, ${ }^{1}$ G. R. SERJEANT, ${ }^{2}$ AND R. J. HAYES ${ }^{3}$
}

From the ${ }^{1}$ Department of Clinical Ophthalmology, Institute of Ophthalmology, Moorfields Eye Hospital, City Road, London ECIV 2PD; the ${ }^{2}$ Medical Research Council Laboratories, University of the West Indies, Mona, Kingston, Jamaica, WI; and the ${ }^{3}$ Tropical Epidemiology Unit, London School of Hygiene and Tropical Medicine, Keppel Street, London WC1

SUMmARY Ophthalmological examinations were performed on 59 of the $74(80 \%)$ children with homozygous sickle cell (SS) disease and on 37 of the $54(69 \%)$ children with sickle cell-haemoglobin $\mathrm{C}$ (SC) disease, aged 5-7.5 years, within the cohort study of sickle cell disease. Arteriolar sheathing was the commonest retinal vessel abnormality, occurring in 30/59 (51\%) SS children and in 11/37 $(30 \%)$ SC children. Peripheral arteriolar closure was observed in $14(24 \%)$ SS children and in 6 $(16 \%)$ SC children. Arteriovenous anastomoses were seen in 3 children, but proliferative retinopathy was not identified. Capillary changes often occurred in patients without confluent closure, suggesting that complex remodelling of the capillary bed may precede retinal nonperfusion. Discrete retinal patches similar to schisis cavities resulting from intraretinal haemorrhages were found in $22(37 \%)$ SS children and in $9(24 \%)$ SC children, but haemorrhages were observed in only 2 patients (1 SS, 1 SC). Vitreous opacities were common and were generally associated with retinal vessel disease. Retinal changes were consistently more common in children with SS disease, though the differences failed to reach statistical significance. The prevalence of peripheral vascular closure and retinal patches showed a significant upward trend with age. These observations contrast with the greater prevalence of proliferative retinopathy characterising SC disease in adults.

Major visual loss in sickle cell disease may result from vitreous haemorrhage or retinal detachment, both consequences of proliferation of retinal blood vessels. It has been suggested ${ }^{12}$ that peripheral arteriolar closure is the initiating event in an orderly progression of vascular changes culminating in the development of proliferative sickle retinopathy (PSR). PSR is more common in SC disease ${ }^{3-5}$ yet there is evidence that peripheral closure is equally common in homozygous sickle cell (SS) disease and sickle cell-haemoglobin C (SC) disease.$^{34}$ This implies that progression to PSR is not inevitable. Spontaneous resolution of PSR may occur more commonly in SS disease, ${ }^{6}$ and the disparity between phenotypic expression of the 2 genetic abnormalities may reflect only a different predisposition to the development of preretinal blood vessels.

Retinal vascular changes in childhood have been reported rarely, ${ }^{7}$ yet identifying early vascular abnormalities and their relationship to PSR may be crucial to the understanding of the genesis of PSR. A cohort study of sickle cell disease in which infants have been

Correspondence to Professor A. C. Bird. followed up from birth has provided an opportunity to assess the early retinal vascular changes in a well documented and representative sample of children with SS and SC disease.

\section{Patients and methods}

Since mid-1973 cord blood samples from approximately $95 \%$ of all nonoperative deliveries at the main Government maternity hospital (Victoria Jubilee Hospital) in Kingston, Jamaica, have been screened by electrophoresis on cellulose acetate and agar gel. ${ }^{8}$ By 1 January 1981 a total of 89020 infants had been screened, with the detection of 290 children with SS disease and 170 children with SC disease. These children, along with age/sex matched controls with a normal haemoglobin (AA) genotype, have been followed up in special clinics operated by the staff of the MRC Laboratories.

At the time of the present study (January 1981) al children with SS or SC disease aged over 5 years were invited to attend for ophthalmic examinations during a 3-week period. Of the available patients $59 / 74$ 
$(80 \%)$ children with SS disease and $37 / 54(69 \%)$ children with SC disease attended. Ten normal control children representing all normal controls with appointments during the 3-week study period were also examined. The average age of each group was 6 years 3 months (range 5-7.5 years).

Visual acuity was measured by Snellen's test type or the illiterate $E$ test at 6 metres. Fundus examination was performed by direct and indirect ophthalmoscopy with the pupils dilated. Fluoroscopy and angiography were carried out in patients with identifiable disease and routinely in those over 6.5 years, amounting to 35 children.

\section{Results}

VISUAL ACUITY

In 8 patients it was impossible to obtain an accurate assessment, but in the remaining 88 children acuity was $6 / 9$ or better.

\section{RETINAL VASCULATURE}

Arteriolar sheathing, as distinct from the altered vascular reflex occurring in diffuse peripheral disease, was recorded in $30 / 59(51 \%)$ SS children and in 11/37 $(30 \%)$ SC children. Opacification of the vessel wall was generally confined to either side of the blood column over long segments, but total opacification was seen in 2 patients in both of whom vessel patency was confirmed by fluoroscopy.

Peripheral closure, diagnosed on the basis of fluorescein angiography or fluoroscopy, was observed in $14 / 59(24 \%)$ SS children and in 6/37 (16\%) SC children (Fig. 1). The extent of closure varied between $60^{\circ}$ and $360^{\circ}$ of the circumference at the periphery and always affected the temporal side.

Circumferential arteriovenous anastomoses (Fig. 1) were visible ophthalmoscopically in 3 patients, all with closure. An elevated vascular loop which leaked fluorescein was observed at the edge of an area of closure in 2 children with SS disease.

Coarsening of the capillary bed (Figs. 2,3) was observed posterior to areas of closure but also occurred in some patients without closure. Other microvascular changes included aneurysmal dilatation of vessels (Fig. 3), arteriolar bypass channels, arteriovenous communications, and abnormal tortuosity (Fig. 4).

Pathological avascular zones in the macular region were not seen.

HAEMORRHAGE

Single peripheral intravitreal haemorrhage occurred in 2 patients (1 SS, $1 \mathrm{SC}$ ). The preretinal blood was not obviously associated with intraretinal haemorrhage or forward vessels, though in both cases the haem-

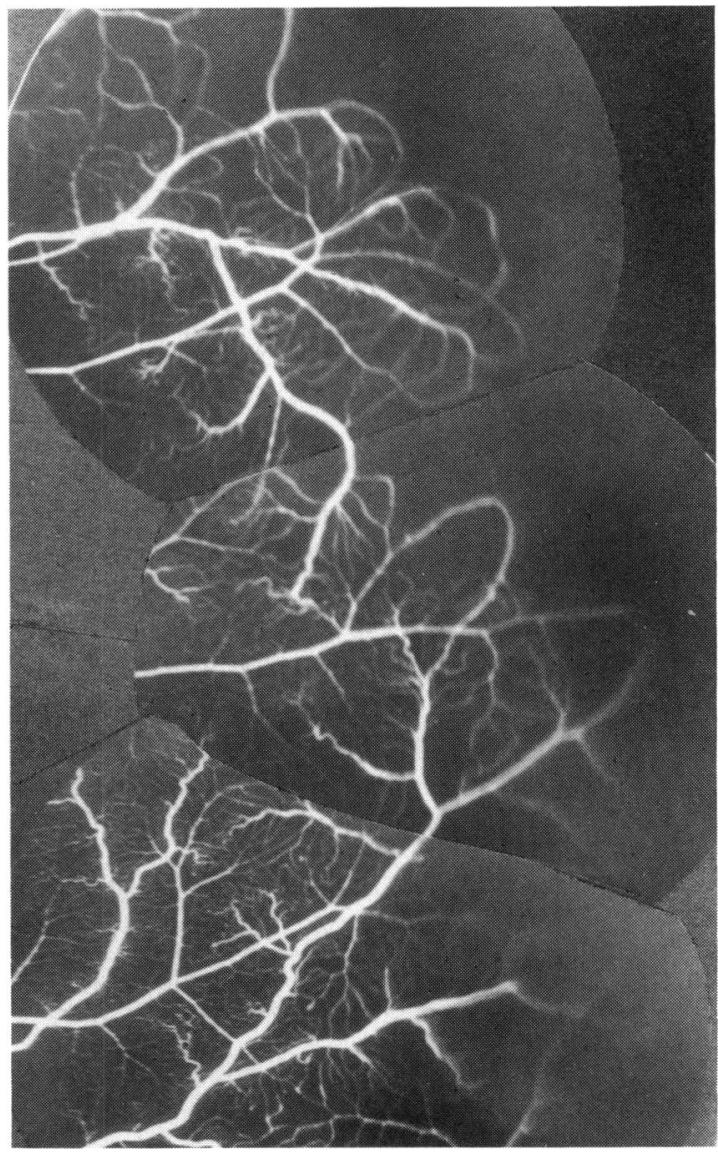

Fig. 1 Fluorescein angiography demonstrating peripheral retinal nonperfusion and arteriovenous anastomoses in a male with HbSS aged 7 years.

orrhage occurred at the junction of perfused and occluded capillary beds. One of these patients had an additional linear intraretinal haemorrhage.

\section{PERIPHERAL RETINAL CHANGES}

Discrete retinal patches of discoloration occurred in $22(37 \%)$ SS children and in $9(24 \%)$ SC children. These lesions varied from 0.5 to $3 \mathrm{~mm}$ in diameter. and there were up to 12 lesions in any eye. Some were flat, varying in colour from brown to grey, and were occasionally associated with irridescent spots within them. Others were raised and were frequently a similar colour to, or darker than, the adjacent retina and were surrounded by a light reflex. One lesion appeared to be cystic. Some patches had a central white spot which itself was occasionally raised. There was no evidence of a recent haemorrhage associated with a patch.

Fluorescein angiography of these lesions was 


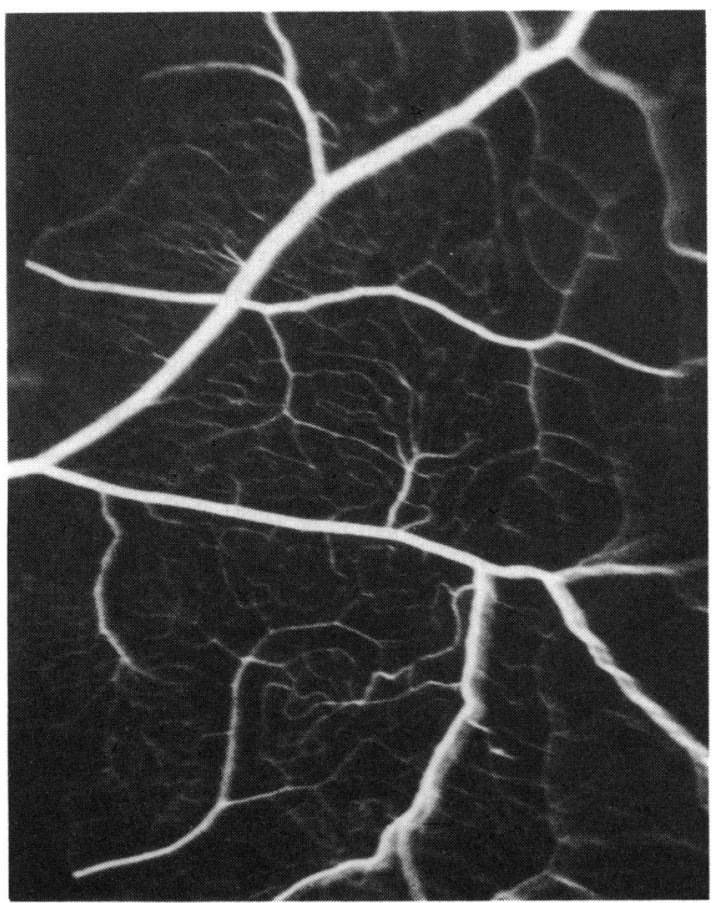

Fig. 2 Fluorescein angiography of the peripheral retina showing coarsening of the capillary bed in a female with HbSS aged 6 years 6 months.

usually normal, although some showed transmission defects at the level of the retinal pigment epithelium. There was no masking by the lesions, and the overlying capillary bed was unaltered.

A diffuse retinal colour change, observed in 27 $(46 \%)$ SS children and in $10(27 \%)$ SC children, consisted of a poorly defined irregular variation in the colour of the peripheral retina, varying between yellow and red, extending in some cases behind the equator but always to the ora serrata. This change was noted predominantly in the inferior retina. Fluorescein angiography showed that masking. leakage, and peripheral closure were not necessarily associated with an area of colour change, though some had transmission defects. Where there was closure in an area of colour change, it could be defined only by angiography.

Only one patient had peripheral retinal whitening, which occurred in one quadrant. This was not associated with closure, masking, or leakage on angiography.

Proliferative retinopathy was not seen in either group in this study.

VITREOUS CHANGES

Greyish condensation of the vitreous base (vitreous veils) was found in $18(31 \%)$ SS patients and in 8 (22\%) SC patients. This appeared as radial multilayered opacities in the peripheral vitreous, and was associated with retinal abnormality in every case except one patient with SC disease, though fluoroscopy was not performed in this case.

\section{RELATIONSHIP BETWEEN AGE AND GENOTYPE}

(Table 1)

Retinal and vitreous changes were observed in all age groups but only peripheral vascular closure $(p<0.05)$ and retinal patches $(p<0 \cdot 01)$ showed a significant upward trend with age (by the Mantel-Haenszel $\chi^{2}$ test for trend with age, allowing for genotype). Closure was seen in a patient as young as 5 years 4 months. Sheathing, peripheral colour change, and vitreous veils failed to show any significant age relationship. All the abnormal findings were more common in SS than in SC disease, but by a similar $\chi^{2}$ test for difference between genotypes and allowing for age they failed to show significant differences.

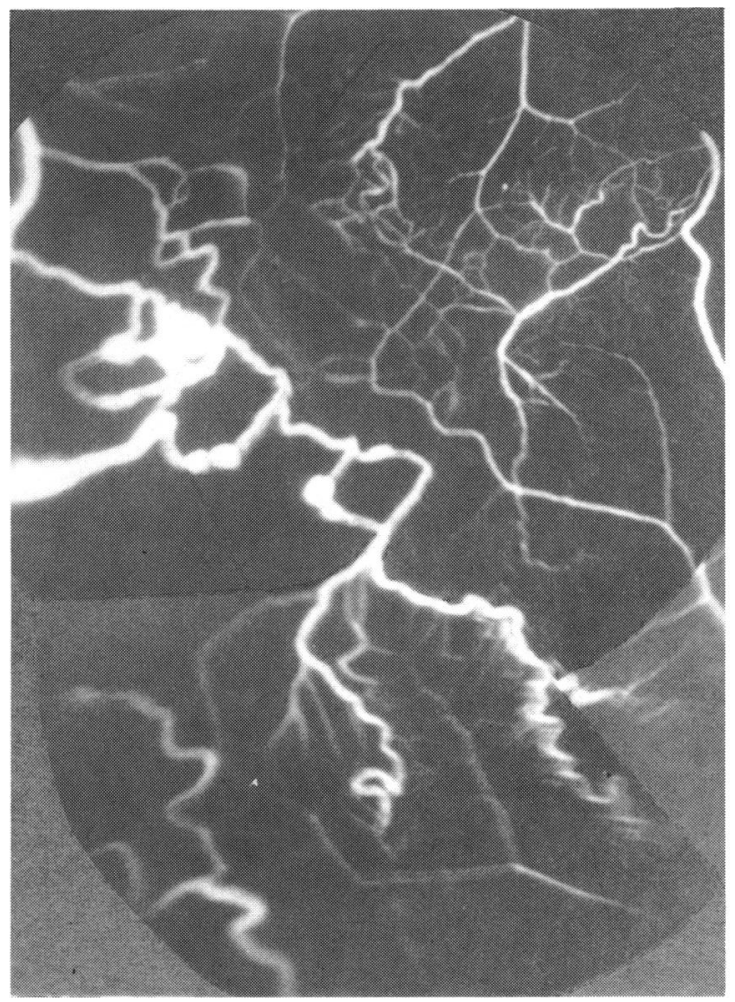

Fig. 3 Fluorescein angiography of peripheral retina showing coarsening of the capillary bed, areas of retinal nonperfusion, and aneurysmal dilatation of retinal vessels in a male with $\mathrm{HbSS}$ aged 6 years 11 months. 
Table 1 Vitreous and retinal changes correlated with age

\begin{tabular}{|c|c|c|c|c|c|c|c|c|c|c|c|c|}
\hline \multirow{2}{*}{$\begin{array}{l}\begin{array}{l}\text { Age } \\
\text { (months) }\end{array} \\
60-71\end{array}$} & \multirow{2}{*}{$\begin{array}{l}\text { Genotype } \\
\text { SS } \\
\text { SC }\end{array}$} & \multirow{2}{*}{$\begin{array}{l}\text { Number } \\
23 \\
10\end{array}$} & \multicolumn{2}{|c|}{ Sheathing } & \multicolumn{2}{|c|}{ Closure } & \multicolumn{2}{|c|}{$\begin{array}{l}\text { Peripheral colour } \\
\text { change }\end{array}$} & \multicolumn{2}{|c|}{ Patches } & \multicolumn{2}{|c|}{$\begin{array}{l}\text { Vitreous } \\
\text { opacity }\end{array}$} \\
\hline & & & $\begin{array}{r}11 \\
2\end{array}$ & $\begin{array}{l}48 \% \\
20 \%\end{array}$ & $\begin{array}{l}3 \\
0\end{array}$ & $13 \%$ & $\begin{array}{r}10 \\
5\end{array}$ & $\begin{array}{l}43 \% \\
50 \%\end{array}$ & $\begin{array}{l}7 \\
1\end{array}$ & $\begin{array}{l}30 \% \\
10 \%\end{array}$ & $\begin{array}{l}6 \\
3\end{array}$ & $\begin{array}{l}26 \% \\
30 \%\end{array}$ \\
\hline $72-83$ & $\begin{array}{l}\text { SS } \\
\text { SC }\end{array}$ & $\begin{array}{l}22 \\
20\end{array}$ & $\begin{array}{r}10 \\
6\end{array}$ & $\begin{array}{l}45 \% \\
30 \%\end{array}$ & $\begin{array}{l}5 \\
4\end{array}$ & $\begin{array}{l}23 \% \\
20 \%\end{array}$ & $\begin{array}{l}9 \\
3\end{array}$ & $\begin{array}{l}41 \% \\
15 \%\end{array}$ & $\begin{array}{l}5 \\
5\end{array}$ & $\begin{array}{l}23 \% \\
25 \%\end{array}$ & $\begin{array}{l}7 \\
3\end{array}$ & $\begin{array}{l}32 \% \\
15 \%\end{array}$ \\
\hline $84-90$ & $\begin{array}{l}\text { SS } \\
\text { SC }\end{array}$ & $\begin{array}{r}14 \\
7\end{array}$ & $\begin{array}{l}9 \\
3\end{array}$ & $\begin{array}{l}64 \% \\
43 \%\end{array}$ & $\begin{array}{l}6 \\
2\end{array}$ & $\begin{array}{l}43 \% \\
29 \%\end{array}$ & $\begin{array}{l}8 \\
2\end{array}$ & $\begin{array}{l}57 \% \\
29 \%\end{array}$ & $\begin{array}{r}10 \\
3\end{array}$ & $\begin{array}{l}71 \% \\
43 \%\end{array}$ & $\begin{array}{l}5 \\
2\end{array}$ & $\begin{array}{l}36 \% \\
29 \%\end{array}$ \\
\hline Total & $\begin{array}{l}\text { SS } \\
\text { SC } \\
\text { Both }\end{array}$ & $\begin{array}{l}59 \\
37 \\
96\end{array}$ & $\begin{array}{l}30 \\
11 \\
41\end{array}$ & $\begin{array}{l}51 \% \\
30 \% \\
43 \%\end{array}$ & $\begin{array}{r}14 \\
6 \\
20\end{array}$ & $\begin{array}{l}24 \% \\
16 \% \\
21 \%\end{array}$ & $\begin{array}{l}27 \\
10 \\
37\end{array}$ & $\begin{array}{l}46 \% \\
27 \% \\
39 \%\end{array}$ & $\begin{array}{r}22 \\
9 \\
31\end{array}$ & $\begin{array}{l}37 \% \\
24 \% \\
32 \%\end{array}$ & $\begin{array}{r}18 \\
8 \\
26\end{array}$ & $\begin{array}{l}31 \% \\
22 \% \\
27 \%\end{array}$ \\
\hline
\end{tabular}

INTERRELATIONSHIPS BETWEEN RETINAL

FINDINGS

When the association between each pair of variables was examined in all age groups and genotypes

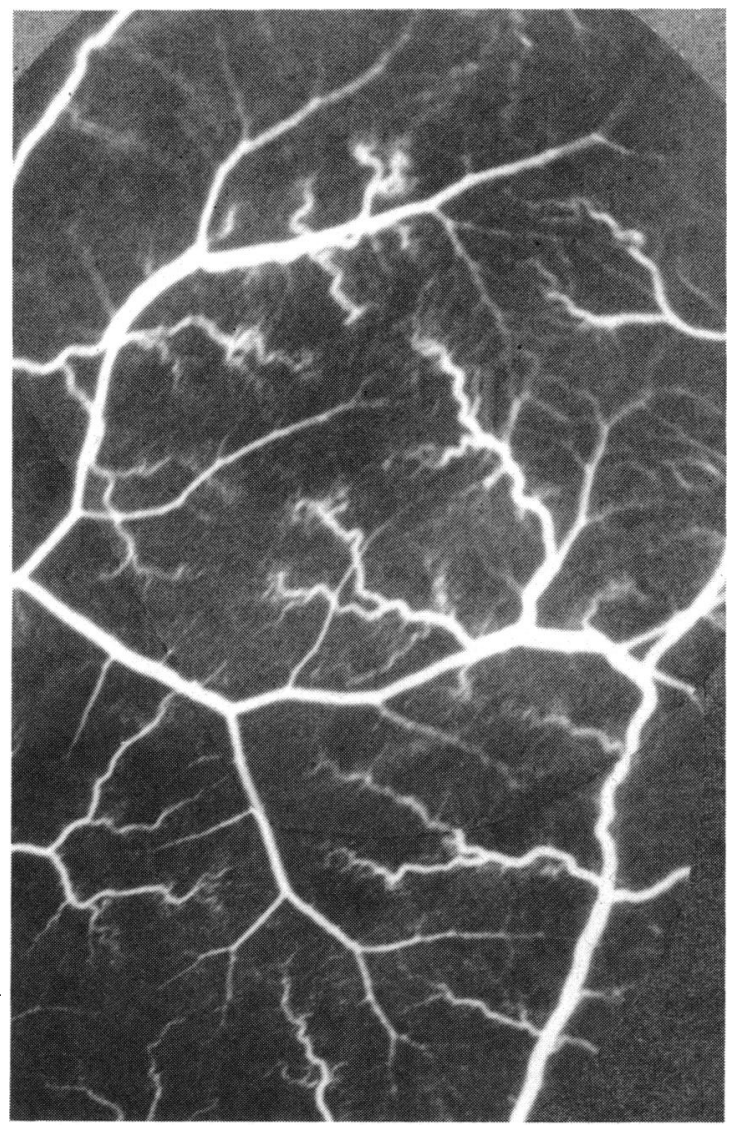

Fig. 4 Fluorescein angiography of peripheral retina showing tortuosity of retinal vessels and an abnormal pattern of arterioles and venules in a female with $\mathrm{HbSS}$ aged 7 years 5 months. combined, highly significant relationships were apparent between closure and sheathing $(\mathrm{p}<0 \cdot 001)$ and closure and retinal patches $(p<0.001)$, and between sheathing and peripheral colour change $(p<0 \cdot 001)$ and sheathing and patches $(p<0 \cdot 01)$. No significant relationships were apparent between peripheral colour change and closure or between peripheral colour change and patches. Of the 20 patients with closure 17 had sheathing and 14 had patches; all patients with closure demonstrated either sheathing or retinal patches (Table 2).

FINDING IN CONTROLS

The retina, retinal vessels, and vitreous were entirely normal in 9 controls, but layered radial opacities in the vitreous were observed in one control.

\section{Discussion}

RETINAL VESSEL CHANGES

This study indicates that retinal vascular disease occurs in both SS and SC disease before the age of 6 years. Peripheral nonperfusion was more common with advancing age, but it is possible that reluctance to perform fluoroscopy on all patients may have led to an underestimate of its prevalence. Although proliferative retinopathy was not seen, arteriovenous anastomoses were apparent in 3 patients; the close temporal relationship between arteriovenous anastomoses and PSR observed in older populations

Table 2 Relationship between arteriolar closure and other retinal findings

\begin{tabular}{lrlrl}
\hline & \multicolumn{3}{l}{ Patients examined (96) } \\
\cline { 2 - 5 } & \multicolumn{2}{c}{ Closure } & \multicolumn{2}{c}{ No closure } \\
\hline Total & 20 & & 76 & \\
Sheathing alone & 6 & $30 \%$ & 15 & $20 \%$ \\
Retinal patches alone & 3 & $15 \%$ & 8 & $11 \%$ \\
Sheathing and patches & 11 & $55 \%$ & 9 & $12 \%$ \\
No sheathing or patches & 0 & & 44 & $58 \%$ \\
\hline
\end{tabular}


(unpublished observations) implies that PSR may soon develop in this patient group.

Opacification of the arteriolar walls was relatively common in children with SS and SC disease but did not occur in control children. In most cases this was apparent only at the edge of the blood column, but in 2 patients the whole blood vessel wall was opaque. The sheathing affecting long segments of the retinal blood vessels simulated sheathing seen in retinal ischaemia rather than the multifocal opacifications seen in retinal vasculitis or following embolism without prolonged ischaemia. However, it is difficult to accept that there had been prolonged retinal ischaemia in the presence of an intact capillary bed, though it is possible that transient ischaemia causes greater endothelial damage in sickle cell disease than in patients with a normal genotype. That vascular obstruction had occurred is supported by the presence of arteriolar by-pass channels seen in one patient without arteriolar occlusion.

In 1971 Goldberg' suggested that retinal arteriolar occlusion was the initiating event in sickle cell retinopathy, but his study on peripheral remodelling ${ }^{9}$ and observations on these children imply a more complex sequence of events. If sheathing is evidence of primary vascular disease, it predates capillary changes in many patients. Coarsening of the capillary beds with large, long capillaries which were fewer than normal occurred without closure in some children and appeared to predate retinal nonperfusion. These observations imply that closure occurs after complex capillary remodelling, which may be a response to intermittent or chronic vascular compromise occurring over a period of time. This is not to deny that the obstruction is at the arteriolar level but to suggest a more complex process than solitary arteriolar obstruction.

\section{NEURORETINAL CHANGES}

Discrete retinal patches of a red or brown colour occasionally containing glistening reflexes were one of the commonest findings, occurring in 31 patients, and were frequently multiple in an affected eye. These lesions had some characteristics previously ascribed to 'schisis cavities,' which are thought to arise from the resolution of intraretinal haemorrhages. ${ }^{1011}$ If the same mechanism applies to these lesions in children, it implies that previous intraretinal haemorrhage must have been common in this group. During the study period an intraretinal haemorrhage was identified in only one patient and another patient had a localised haemorrhage in front of the retina which might have resulted from an intraretinal haemorrhage rupturing through the inner limiting membrane. The presence of a normal capillary bed in many of the patches suggests that the process which gives rise to haem- orrhage, and the haemorrhage itself, do not necessarily have any discernible affect on the retinal vasculature.

Peripheral retinal colour changes did not occur in controls and were presumably related to sickle cell disease. The colour changes were not due to retinal pigment epithelial abnormalities as fluorescein angiography showed no alteration of pigment epithelial transmission characteristics. Condon and Serjeant ${ }^{34}$ attributed whitening of the peripheral retina to oedema which resolved as the neuroretina became thinner, but fluorescein angiography showed no evidence of retinal oedema in the present study. Intermittent vascular obstruction might cause multifocal and ill-defined areas of retinal thinning due to infarction, with consequent changes of the vitreous base and inner limiting membrane. This would be homologous to the facets seen in the posterior retina. ${ }^{12}$ Such a hypothesis could be tested only by histopathological examination of the affected eyes.

\section{VITREOUS CHANGES}

Layered radial opacities in the vitreous base were common in children with SS and SC disease but also occurred in one control. Retinal vascular disease would be expected to influence the vitreous, and vitreous detachment occurs early in patients with sickle retinal vascular disease. All but one of the patients with vitreous veils had signs of retinal vascular disease.

Few controls were examined, so that identification of abnormalities was based partly on comparison with known fundus appearances. However, striking retinal changes were frequent in the study group, and it is apparent that retinal vascular disease is well established in children between 5 and 7.5 years. Although qualitatively similar in SS and SC disease, most retinal vessel abnormalities were more common in SS disease in contrast with a higher prevalence of PSR observed in SC disease during adult life. Apart from the eye, vascular disease is accepted to be more common in SS disease, and our evidence implies that this also applies to vessels in the peripheral retina. If this is confirmed, then the high prevalence of PSR in SC disease must be related to factors other than simple vessel occlusion.

We are grateful to Mr Patrick Condon for valuable discussion. This work was supported in part by grant PHS 15168 from the National Heart Lung and Blood Institute.

\footnotetext{
References

1 Goldberg MF. Classification and pathogenesis of proliferative sickle retinopathy. Am J Ophthalmol 1971; 71: 649-65.

2 Goldberg MF. Natural history of untreated proliferative sickle retinopathy. Arch Ophthalmol 1971; 85: 428-37.
} 
3 Condon PI, Serjeant GR. Ocular findings in homozygous sickle cell disease in Jamaica. Am J Ophthalmol 1972; 73: 533-43.

4 Condon PI, Serjeant GR. Ocular findings in hemoglobin SC disease in Jamaica. Am J Ophthalmol 1972; 74: 931-41.

5 Welch RB. Goldberg MF. Sickle-cell hemoglobin and its relation to fundus abnormality. Arch Ophthalmol 1966; 75: 353-62.

6 Condon PI, Serjeant GR. Behaviour of untreated proliferative sickle retinopathy. Br J Ophthalmol 1980; 64: 404-11.

7 Condon PI. Grey R. Serjeant GR. The ocular findings in children with SC disease in Jamaica. Br J Ophthalmol 1974; 58: 644-9.

8 Serjeant BE. Forbes M, Williams LL, Serjeant GR. Screening cord bloods for the detection of sickle cell disease in Jamaica. Clin Chem 1974; 20: 666-9.
9 Galinos SO, Asdourian GK. Woolf MB, et al. Spontaneous remodeling of the peripheral retinal vasculature in sickling disorders. Am J Ophthalmol 1975; 79: 853-70.

10 Asdourian K. Nagpal KC. Goldbaum M. Patrianakos D. Goldberg MF. Rabb M. Evaluation of the retinal black sunburst in sickling haemoglobinopathies. Br J Ophthalmol 1975; 59: $710-6$.

11 Jampol LM, Condon P. Dizon-Moore R. Serjeant G. Schulman JA. Salmon-patch hemorrhages after central retinal artery occlusion in sickle cell disease. Arch Ophthalmol 1981: 99: 237-40.

12 Goldbaum MH. Retinal depression sign indicating a small retinal infarct. Am J Ophthalmol 1978; 86: 45-55. 